\title{
Rhabdomyosarcoma of the uterus in an adult patient with osteopetrosis: a case report
}

\author{
Soheila Aminimoghaddam ${ }^{1}$, Ali Rahbari ${ }^{2}$ and Roghayeh Pourali ${ }^{3^{*}}$
}

\begin{abstract}
Background: Uterine sarcoma accounts for 3-7\% of uterine malignant neoplasms. It is more aggressive than epithelial neoplasms, and patients have a poor prognosis. Rhabdomyosarcoma is classified as a heterologous uterine sarcoma. It is the most common soft tissue malignancy in children while rare in adults. In young patients, the majority of genital tract rhabdomyosarcomas occur in vagina; however, the most common site of gynecologic rhabdomyosarcoma is cervix followed by uterine corpus, in adults. Uterine corpus rhabdomyosarcoma is rare in adults. Diagnosis of pure rhabdomyosarcoma in uterus involves widespread and perfect sampling as well as precise histopathological evaluation to uncover any epithelial component.

Case presentation: Here we report a case of pure rhabdomyosarcoma of uterine corpus in a 60-year-old Iranian postmenopausal female who had osteopetrosis, presenting with 8-month heavy vaginal bleeding and a protruding cervical mass. She is alive on 18-month follow-up after treatment.

Conclusions: Rhabdomyosarcoma of uterine corpus is rare in adults. Diagnosis of pure rhabdomyosarcoma in uterus involves widespread and perfect sampling as well as precise histopathological evaluation to uncover any epithelial component. Treatment options in adult gynecological rhabdomyosarcoma are based on studies in younger patients, and more studies may help us choose the best approach for improving outcome.
\end{abstract}

Keywords: Rhabdomyosarcoma, Uterus, Sarcoma

\section{Introduction}

Rhabdomyosarcoma (RMS) is an aggressive tumor that tends to develop in children and younger patients [1]. A large majority of genital tract RMSs occurs in infants' and adolescents' vagina [2]. RMS of uterine corpus either occurs as a component of biphasic uterine tumor (adenosarcoma or carcinosarcoma) or can be a pure heterologous tumor [3, 4]. Pure uterine RMS is rare in adult patients and difficult to diagnose. Accurate diagnosis of these tumors depends on precise histopathological

*Correspondence: Roghayehpourali@ymail.com

${ }^{3}$ Department of Obstetrics and Gynecology, Jam Hospital, Fajr Street, Motahari Street, 1588657915 Tehran, Iran

Full list of author information is available at the end of the article evaluation [5]. We hereby report a case of pure RMS of uterine corpus in a 60-year-old postmenopausal female who had osteopetrosis. There is limited experience with RMS management in adults. Older age, widespread disease at the time of diagnosis, and unfavorable histologic variants such as pleomorphic and alveolar led to poor outcomes in adult patients despite multidisciplinary approach. Reviewing rare cases can result in more rapid diagnosis and improved treatment and, consequently, best possible survival rate.

\section{Case report}

A 60-year-old Iranian female patient attended our emergency department with complaints of heavy vaginal bleeding during last 8 months. In her medical history, she 
had three vaginal deliveries, diabetes mellitus, depression, and osteopetrosis. Her menopause started at 50 years of age. She did not report any history of sexually transmitted infection or receiving hormonal medications. Her medications included metformin $(500 \mathrm{mg}$ twice a day), sertraline (50 mg daily), vitamin D (1000 mg daily), and calcium (500 mg daily). She had undergone surgery twice over the last 10 years, due to fracture of lower extremities. Her family history was unremarkable.

She was admitted to our hospital. Hemoglobin level was $6 \mathrm{~g} / \mathrm{dl}$ at the time of admission. The other hematologic and biochemistry tests revealed no significant problems. On pelvic examination, which was performed under anesthesia, we found a remarkably enlarged uterus and a $10-\mathrm{cm}$ soft hemorrhagic mass originating from posterior part of cervix and protruded into vagina.

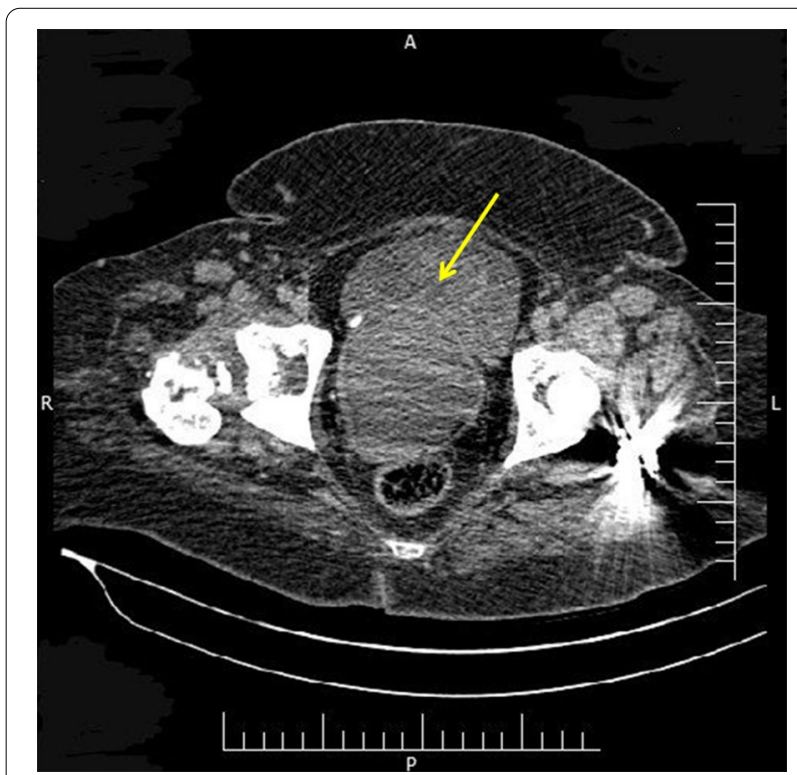

Fig. 1 A large mass (yellow arrow) in posterior wall of uterus in axial-view CT scan
Excisional biopsy was performed. Abdominopelvic computerized tomography (CT) scans revealed a large uterus, a 15- $\mathrm{cm}$ pelvic mass in posterior wall of uterus (Fig. 1), and enlarged pelvic lymph nodes. Chest CT scan and whole-body bone scan were normal. Pathology reported the cervical mass as a high-grade sarcoma in favor of pleomorphic rhabdomyosarcoma.

After a multidisciplinary meeting, the patient was treated with multiagent neoadjuvant chemotherapy. We prescribed intravenous vincristine $(2 \mathrm{mg})$, actinomycinD $(1 \mathrm{~g})$, and cyclophosphamide (1200 mg) (VAC) every 3 weeks for six cycles. Delayed radical hysterectomy, bilateral salpingoophorectomy (BSO), and pelvic lymph node dissection (PLND) were performed due to large bulky tumor and partial response to initial chemotherapy. Her postoperative condition was appropriate, and she was discharged 3 days after surgery. Following discharge, external pelvic irradiation (total dose of $5040 \mathrm{cGy}$ in 28 fractions) was performed in 6 weeks. No complications, such as radiation cystitis or proctitis, occurred. She signed an informed consent form and gave us permission to report her disease. She was followed up every 3 months and was free of disease 18 months after treatment (Figure 2).

\section{Pathology report}

Grossly, the tumor was cream-colored and fleshy, measuring $10 \times 8 \times 6 \mathrm{~cm}$, filling entire endometrial cavity, and protruding into endocervical canal (Fig. 3). Microscopically, the tumor was placed in endometrium with infiltrative border, and the myometrial invasion was less than $50 \%$. In high-power microscopic field, rhabdoid cells were present with abundant bright eosinophilic cytoplasm and atypical enlarged nucleus (Fig. 4a). The tumor displayed variable degrees of necrosis, and tumor giant cells were present. Neither epithelial nor other heterologous component were seen. Numerous mitotic figures, including atypical forms and solid sheets of cells separated with fibrotic bands, were present (Fig. 4b).

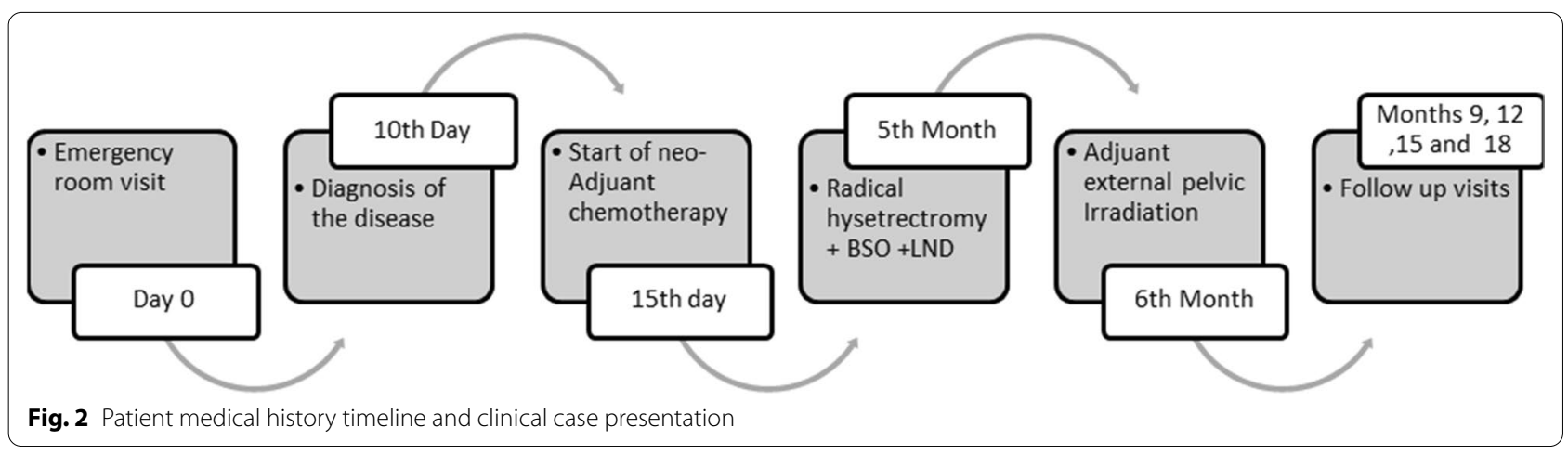




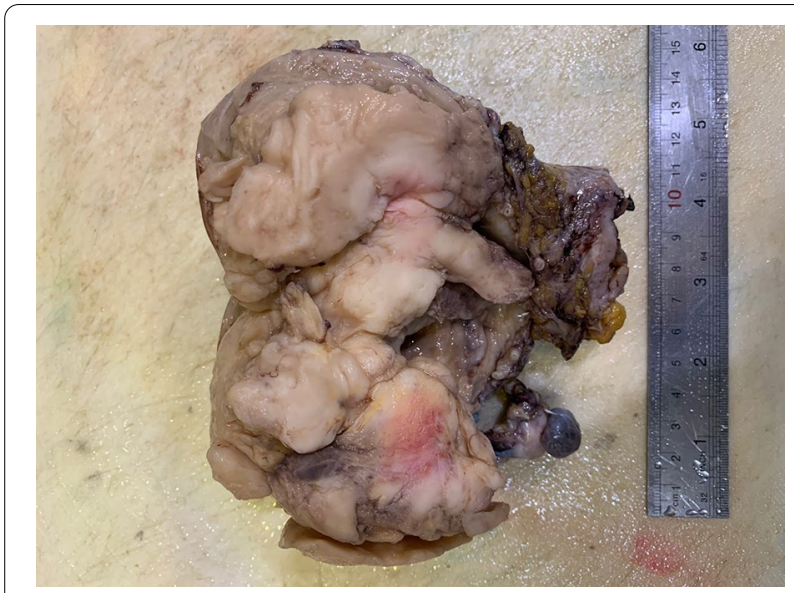

Fig. 3 Gross tumor showing cream-colored fleshy mass filling entire endometrial cavity
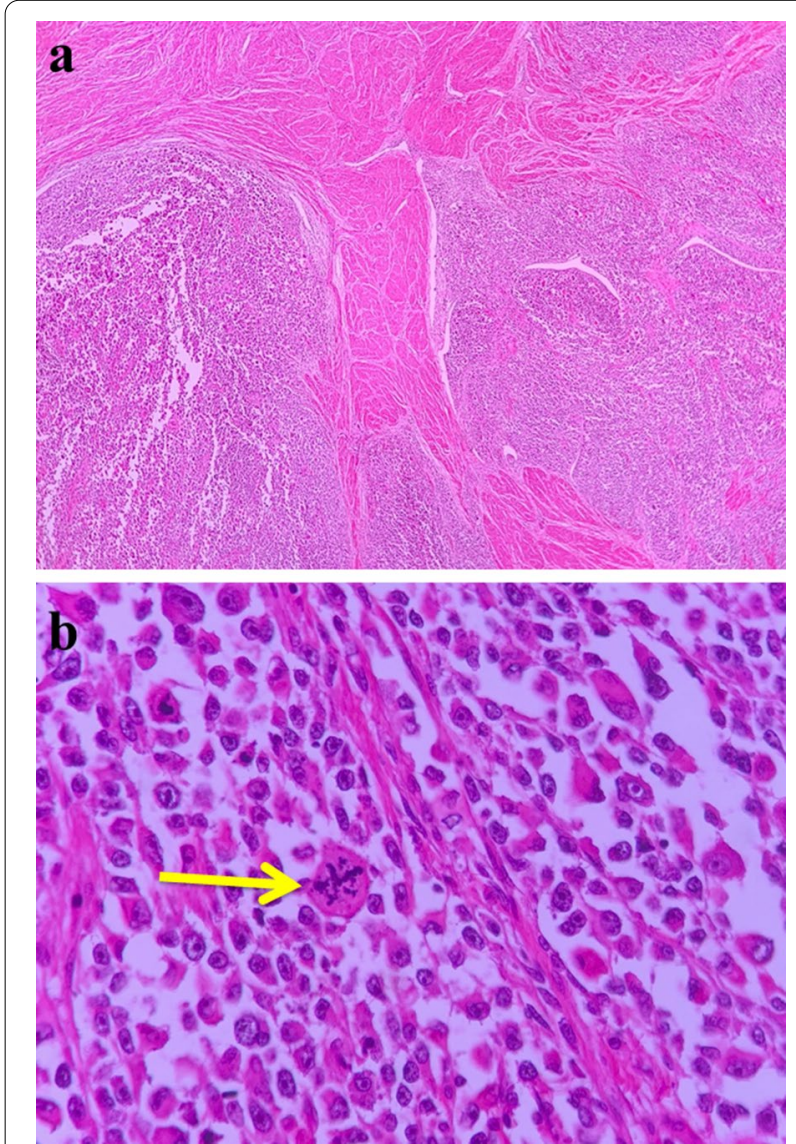

Fig. 4 a Infiltration of tumor within myometrium. b Rhabdoid cells with eosinophilic brightly abundant cytoplasm and numerous mitotic figures (yellow arrow)

These histologic patterns and cytological features describe the solid variant of alveolar subtypes of RMS. There was no lymphovascular space invasion. All 14 pelvic lymph nodes, cervix, vaginal margins, adnexa parameters, and peritoneal washing fluid were free of tumor. Immunohistochemistry (IHC) test showed positive desmin (Fig. 5a), MyoD1 (Fig. 5b), and myogenin (Fig. 5c) cytoplasmic staining.

\section{Discussion}

Uterine sarcoma accounts for $3-7 \%$ of uterine malignant neoplasms and is more aggressive in comparison with epithelial neoplasms $[4,6]$. Uterine sarcomas are classified as homologous, including elements that are normally found in the uterus (endometrial stromal sarcoma, undifferentiated sarcoma, fibrosarcoma, leiomyosarcoma) or heterologous, including sarcomatous components that are not usually found in the uterus (rhabdomyosarcoma , chondrosarcoma, osteosarcoma, liposarcoma). RMS is the most common soft tissue malignancy in children, and a remarkable majority of genital tract RMSs occur in vagina in infants and adolescents [2].Pure heterologous RMS of uterine corpus is rare in adults. Prognosis and survival rate of RMS is disappointing in adult patients.

We hereby presented a case of uterine alveolar RMS in a 60-year-old postmenopausal female patient. We searched PubMed and Scopus for English original articles, letters, and short communications with keywords: "Rhabdomyosarcoma" AND "Uterus" since 1972. Articles that reported rhabdomyosarcoma in corpus of uterus in adults were reviewed if their full text was available. Table 1 summarizes a series of these cases from medical literature. These articles reported 41 patients between 22 and 90 years of age of which 21 patients $(51.2 \%)$ had pleomorphic type, 9 patients (21.9\%) had embryonal type, and 6 patients $(14.6 \%)$ had alveolar type RMS. The tumor size ranged from 5 to $20 \mathrm{~cm}$. Different management approaches were considered for each patient, including surgery and adjuvant and/or neoadjuvant chemotherapies. Thirty-one patients (75.6\%) had undergone total hysterectomy $(\mathrm{TH})+$ bilateral salpingoophorectomy (BSO) (2 subtotal hysterectomy), and 19 patients (46.3\%) had received adjuvant and/or neoadjuvant treatment with chemotherapy and/or irradiation. Also, 21 patients (53\%) died within a mean duration of 12.9 months after initial diagnosis or therapy.

Previous pelvic irradiation and long-term use of tamoxifen are among the risk factors for developing uterine RMS [7]. Our patient did not have these risk factors, but she had history of fracture in lower extremities due to osteopetrosis twice, while none of these cases had similar comorbidity and no correlation was found between RMS and osteopetrosis.

The histologic differential diagnosis of uterine RMS is endometrial stromal sarcoma, leiomyosarcoma, adenosarcoma/carcinosarcoma. As we mentioned earlier, 


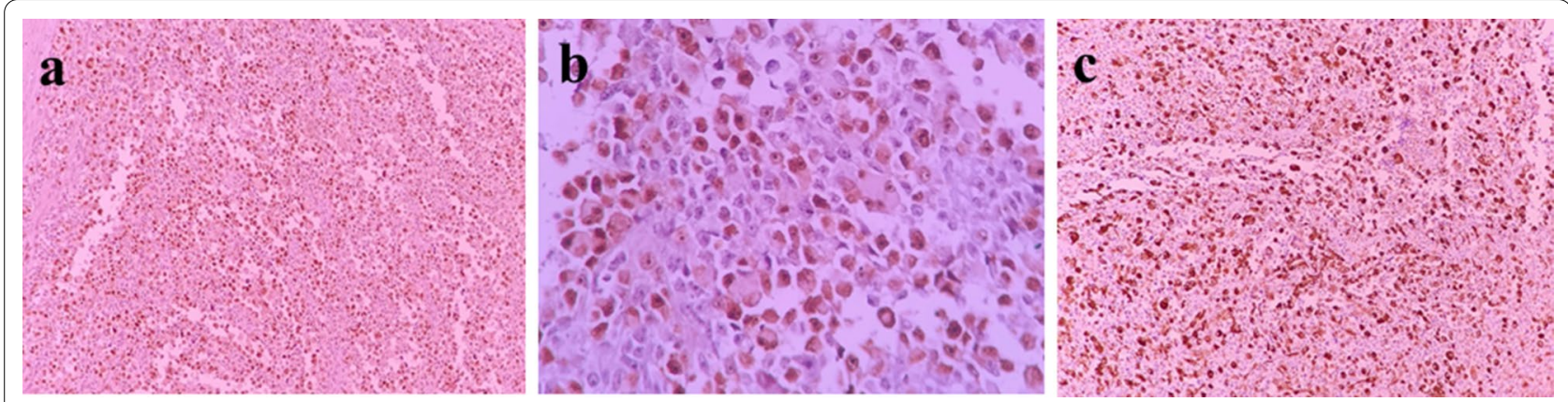

Fig. 5 a Positive for desmin IHC staining in tumor cells. b Positive for MyoD1 IHC staining in tumor cells. c Positive for myogenin $I H C$ staining in tumor cells

diagnosis of pure RMS in uterus involves precise histopathological evaluation. Widespread and perfect sampling is necessary to uncover any epithelial component. IHC test can help us to evaluate any suspected areas [5]. IHC staining identifies muscle-specific proteins such as actin, myosin, myoglobin, desmin, and MyoD1. Rhabdomyosarcoma is classified into four main subtypes: embryonal, alveolar, spindle cell/sclerosing, and pleomorphic. Myoglobin and desmin are positive in most RMS cases, while epithelial markers are not detectable [8]. Fluorescent in situ hybridization (FISH) and reversetranscription polymerase chain reaction (RT-PCR) methods can detect fusion genes such as PAX3_FOXO 1 and PAX7_FOXO1 that are found in alveolar RMS [9]. IHC staining was positive for cytoplasmic desmin, MyoD1, and myoglobin in this patient, but cytogenetic tests were not available.

Ferguson et al. studied 15 women with gynecologic RMS and showed that the most prevalent site of the gynecologic RMS is uterine cervix, followed by uterine corpus. In this study, the 5-year disease-specific survival (DSS) was $29 \%$, and older age, widespread disease at the time of diagnosis, and unfavorable histologic variants such as pleomorphic and alveolar led to poor outcomes in adults [10].

Enzo Ricciardi et al. studied 15 patients with primary cervical RMS . Vaginal bleeding and pelvic mass were the most common symptoms, and Intergroup Rhabdomyosarcoma Study Group (IRS) clinical staging was the best predictor of prognosis [11]. This case presented with heavy vaginal bleeding and a large protruding cervical mass.

There is limited experience with RMS treatment in adults, and a combined modality is considered based on IRS group studies in younger patients [12]. Complete excision of localized tumor, if feasible, followed by chemotherapy or radiotherapy is a common approach.

Maha et al. evaluated 137 patients with nonmetastatic gynecologic RMS, in a systematic review. Surgery was the main approach for local control of tumor in all patients [13]. According to the suggested scheme in this study, our patient was in the high-risk group owing to a large bulky pelvic mass, heavy vaginal bleeding, and alveolar variant of RMS. Therefore, we chose neoadjuvant chemotherapy (NACT) followed by definitive surgery.

In a retrospective analysis of 171 patients (older than 18 years of age), Ferrari et al. concluded that RMS responds to chemotherapy in adults exactly as it does in children, and there is no reason to select different approaches [14].

Luca Bergamaschi et al. reported 95 adult patients with RMS in a prospective single-center case series. The treatment recommendation was a multidisciplinary approach that included surgery, chemotherapy, and radiotherapy. Chemotherapy was recommended for all patients. It consisted of a multidrug treatment, alternating the ifosfamide, vincristine, and actinomycin-D (IVA) regimen with ifosfamide, vincristine, and adriamycin (IVAd) or ifosfamide, vincristine, and etoposide (IVE). Delayed surgery was performed after three to four courses of chemotherapy. Radiotherapy (with a conventional fractionation and doses ranging from 50 to $60 \mathrm{~Gy}$ ) was suggested in all cases of alveolar, not otherwise specified (NOS) RMS, and embryonal RMSs that were incompletely resected at diagnosis. In this study, the 5-year event-free and overall survival rates were $33.6 \%$ and $40.3 \%$, respectively [15]

We used neoadjuvant chemotherapy, including VAC regimen, for the patient, and she received external pelvic irradiation with a total dose of 5040 cGy within 6 weeks after surgery. 
Table 1 Management and outcomes in women with uterine corpus RMS

\begin{tabular}{|c|c|c|c|c|c|c|}
\hline & References & RMS type & Age & Tumor size & Treatment & Outcome \\
\hline \multirow[t]{3}{*}{1} & Oluwole & Pleomorphic & 51 years & $7 \times 5.8 \times 3.4 \mathrm{~cm}$ & $\begin{array}{l}\mathrm{TH}+\mathrm{BSO}+\mathrm{RPLND}+\text { resection of } \\
\text { gross tumors }\end{array}$ & Death due to disease 0.5 months \\
\hline & \multirow[t]{3}{*}{ Fadare et al. [16] } & & 74 years & $14 \times 6.5 \times 5.1 \mathrm{~cm}$ & $\begin{array}{l}\mathrm{TH}+\mathrm{BSO}+\mathrm{PPLND}+\text { resection of } \\
\text { gross tumors }\end{array}$ & Lost to F/U \\
\hline & & & 79 & $10 \times 6 \times 4 \mathrm{~cm}$ & $\begin{array}{l}\text { TH + BSO + PPLND + resection of } \\
\text { gross tumors + adj pelvic RT }\end{array}$ & Death due to disease 6.3 months \\
\hline & & & 68 years & $9.3 \times 7.4 \times 4.2 \mathrm{~cm}$ & $\begin{array}{l}\text { TH }+ \text { BSO + PPLND + resection of } \\
\text { gross tumors + adj pelvic RT + VAC } \\
\text { chemotherapy }\end{array}$ & Death due to disease 19 months \\
\hline 2 & Sohsuke Yamada et al. & Embryonal & 55 years & $11 \times 7 \mathrm{~cm}$ & $\mathrm{TH}+\mathrm{BSO}$ & 6 month F/U free of disease \\
\hline 3 & Garrett La et al. & Embryonal & 28 years & $5.6 \mathrm{~cm}$ & $\begin{array}{l}\text { TH + omentectomy + VAC chemo- } \\
\text { therapy }\end{array}$ & 40 week F/U during chemo \\
\hline 4 & Masaharu Fukunaga & Alveolar & 72 years & $6 \mathrm{~cm}$ & $\begin{array}{l}\text { TH + BSO + PLND + resection of } \\
\text { gross tumors + adj chemotherapy }\end{array}$ & Death due to disease 12 months \\
\hline 5 & Masashi Takano et al. & Embryonal & 76 years & $15 \times 17 \mathrm{~cm}$ & $\mathrm{TH}+\mathrm{BSO}+$ adj chemotherapy & 10 months F/U after surgery \\
\hline 6 & Carolina Chmaj et al. & Pleomorphic & 66 years & $8.2 \times 6.4 \mathrm{~cm}$ & $\mathrm{TH}+\mathrm{BSO}+$ adj chemotherapy & Death $2.5 \mathrm{y} / \mathrm{s}$ after surgery \\
\hline \multirow[t]{2}{*}{7} & \multirow[t]{2}{*}{ Donkers et al. } & Embryonal & 90 years & 450 gram uterus & $\mathrm{TH}+\mathrm{BSO}$ & $\begin{array}{l}\text { Death } 7 \text { months after surgery } \\
\text { probably due to CHF }\end{array}$ \\
\hline & & Pleomorphic & 56 & 150 gruterus & $\begin{array}{l}\mathrm{TH}+\mathrm{BSO}+\text { neoadj and adj chemo- } \\
\text { radiation }\end{array}$ & Death $6.5 \mathrm{y} / \mathrm{s}$ after surgery \\
\hline 8 & Roberto Chiarle & Alveolar & 80 years & $9 \mathrm{~cm}$ & $\mathrm{TH}+\mathrm{BSO}+$ adj radiotherapy & Death 4 months after surgery \\
\hline 9 & Hideo Teshima et al. & Embryonal & 52 & 320 gruterus & $\begin{array}{l}\mathrm{TH}+\mathrm{BSO}+\mathrm{PLND}+\text { adj chemo- } \\
\text { therapy }\end{array}$ & 30 month F/U after surgery \\
\hline 10 & Fabrice Leung et al. & Pleomorphic & 68 years & $5 \times 5 \times 2 \mathrm{~cm}$ & $\mathrm{TH}+\mathrm{BSO}$ & 12 month F/U after surgery \\
\hline 11 & Reynolds et al. & Embryonal & 65 years & $27 \times 17 \times 15 \mathrm{~cm}$ & $\begin{array}{l}\text { TH + BSO + partial cystec- } \\
\text { tomy + omentectomy + PLND }\end{array}$ & Death 10 days after surgery \\
\hline 12 & Siegal et al. & Unavailable & 69 years & $6.1 \times 5 \times 4.9 \mathrm{~cm}$ & $\begin{array}{l}\mathrm{TH}+\mathrm{BSO}+\mathrm{PPLND}+\text { resection of } \\
\text { gross tumors + adj pelvic RT }\end{array}$ & F/U 3 months after surgery \\
\hline \multirow[t]{6}{*}{13} & \multirow[t]{6}{*}{ Pinto et al. [5] } & Alveolar & 40 years & $12 \mathrm{~cm}$ & Chemotherapy & 18 month F/U after surgery \\
\hline & & Pleomorphic & 68 years & $13.6 \mathrm{~cm}$ & Chemotherapy & Death 10 months after surgery \\
\hline & & Pleomorphic & 65 years & Unavailable & Chemotherapy & 26 month F/U after surgery \\
\hline & & Pleomorphic & 62 years & $15.2 \mathrm{~cm}$ & Hospice care & Death 4 months after surgery \\
\hline & & Pleomorphic & 70 years & $13 \mathrm{~cm}$ & Chemotherapy & 9 month F/U after surgery \\
\hline & & Alveolar & 64 years & $14.5 \mathrm{~cm}$ & Hospice care & Death 6 weeks after surgery \\
\hline 14 & Sara Alavi et al. & Pleomorphic & 73 years & $6.5 \times 6 \times 5 \mathrm{~cm}$ & $\mathrm{TH}+\mathrm{BSO}$ & Unavailable \\
\hline 15 & Norio Motoda et al. & Alveolar & 50 years & $10 \mathrm{~cm}$ & Partial resection & Death 19 days after surgery \\
\hline 16 & Afshan Ambreen et al. & Embryonal & 22 & $8 \times 10 \mathrm{~cm}$ & $\mathrm{TH}+\mathrm{BSO}+$ adj chemoradiation & Death 14 months after surgery \\
\hline 17 & Aljehani et al. & Embryonal & 54 years & $10 \mathrm{~cm}$ & Palliative pelvic radiotherapy & Unavailable/new case \\
\hline 18 & Goldstein et al. & Unavailable & 73 years & Unavailable & $\mathrm{TH}+\mathrm{BSO}+$ adj chemotherapy & 11 month F/U after surgery \\
\hline 19 & Ashley S. Case et al. & Alveolar & 21 & $10.2 \times 8.2 \mathrm{~cm}$ & $\begin{array}{l}\mathrm{TH}+\mathrm{BSO}+\text { neoadj and adj chemo- } \\
\text { therapy }\end{array}$ & 20 month F/U after surgery \\
\hline 20 & Podczaski et al. & Pleomorphic & 73 years & $10 \times 7 \times 5 \mathrm{~cm}$ & $\begin{array}{l}\mathrm{TH}+\mathrm{BSO}+\text { omentec- } \\
\text { tomy }+ \text { PPLND + adj pelvic radiation }\end{array}$ & Death 3 months after surgery \\
\hline 21 & Dae Woon Kim et al. & Spindle cell & 76 years & $20 \times 15 \times 7 \mathrm{~cm}$ & Subtotal hysterectomy + BSO & Death 3 months after diagnosis \\
\hline 22 & Mutsumi Kuroki et al. & Unavailable & 36 years & Unavailable & Chemotherapy & Death 5 months after diagnosis \\
\hline 23 & Okada et al. [7] & Pleomorphic & 53 years & $15 \mathrm{~cm}$ & Radical hysterectomy + adj radiation & Recurrence 2 months after surgery \\
\hline \multirow[t]{2}{*}{24} & \multirow[t]{2}{*}{ Mccluggage et al. } & Spindle cell & 28 years & $12 \mathrm{~cm}$ & $\begin{array}{l}\text { Modified radical hysterec- } \\
\text { tomy + PLND + adj chemoradiation }\end{array}$ & F/U 2 years after surgery \\
\hline & & Pleomorphic & 67 years & $5 \mathrm{~cm}$ & Subtotal hysterectomy + BSO & Death 3 days after surgery \\
\hline \multirow[t]{3}{*}{25} & \multirow[t]{3}{*}{ Hart et al. [17] } & Embryonal & 22 years & 100 gruterus & $\begin{array}{l}\text { Radical hysterectomy }+ \text { adj and } \\
\text { neoadj chemotherapy VAC }\end{array}$ & F/U 4.4 years after surgery \\
\hline & & Pleomorphic & 70 years & 450 gruterus & $\mathrm{TH}+\mathrm{BSO}$ & Death 4 months after surgery \\
\hline & & Pleomorphic & 56 years & Unavailable & Palliative chemotherapy & Death 6 weeks after diagnosis \\
\hline
\end{tabular}


Table 1 (continued)

\begin{tabular}{|c|c|c|c|c|c|c|}
\hline & References & RMS type & Age & Tumor size & Treatment & Outcome \\
\hline 26 & Kevin Holcomb et al. & Pleomorphic & 63 years & $6 \times 6 \times 2 \mathrm{~cm}$ & $\mathrm{TH}+\mathrm{BSO}$ & Death 4 years after surgery \\
\hline 27 & S. Yeasmin et al. & Pleomorphic & 60 years & Unavailable & $\begin{array}{l}\mathrm{TH}+\mathrm{BSO}+\mathrm{PPLND}+\text { adj chemo- } \\
\text { radiation }\end{array}$ & Death 20 months after surgery \\
\hline 28 & Jaworski et al. & Pleomorphic & 71 years & 1200 gram uterus & $\mathrm{TH}+\mathrm{BSO}$ & F/U 7 months after surgery \\
\hline \multirow[t]{2}{*}{29} & Katalin Borka et al. & Pleomorphic & 67 years & $15 \mathrm{~cm}$ & $\begin{array}{l}\mathrm{TH}+\mathrm{BSO}+\mathrm{PPLND}+\text { adj chemo- } \\
\text { therapy }\end{array}$ & F/U 12 months after surgery \\
\hline & Aminimoghaddam et al. & Alveolar & 60 years & $10 \times 8 \times 6 \mathrm{~cm}$ & $\begin{array}{l}\text { TH + BSO + PPLND + neoadj chem- } \\
\text { otherapy + adj pelvic irradiation }\end{array}$ & Alive at 12 month $F / U$ \\
\hline
\end{tabular}

TH total hysterectomy, BSO bilateral salpingoophorectomy, PLND pelvic lymph node dissection, PPLND pelvic and paraaortic lymph node dissection, adj adjuvant, neoadj neoadjuvant, $F / U$ follow-up, CHF chronic heart failure

\section{Conclusion}

RMS of uterine corpus is rare in adults. It is an aggressive tumor with a poor outcome, despite multidisciplinary approach. Histopathological criteria, IHC staining, and molecular studies differentiate RMS from the other uterine sarcomas. More studies are needed on treatment options in adults.

\section{Abbreviations}

RMS: Rhabdomyosarcoma; CT Scan: Computerized tomography; BSO: Bilateral salpingoophorectomy; PLND: Pelvic lymph node dissection; IHC: Immunohistochemistry; TH: Total hysterectomy; FISH: Fluorescent in situ hybridization; RT-PCR Reverse-transcription polymerase chain reaction; NACT: Neoadjuvant chemotherapy; IVA: Ifosfamide, vincristine, actinomycin-D; IVAd: Ifosfamide, vincristine, adriamycin; IVE: Ifosfamide, vincristine, etoposide; VAC: Vincristine, actinomycinD, cyclophosphamide; DSS: Disease-specific survival; IRS: Intergroup Rhabdomyosarcoma Study Group; F/U: Follow-up; CHF: Chronic heart failure.
\end{abstract}

\section{Acknowledgements}

Not applicable.

\section{Authors' contributions}

SA performed management steps for the patient. AR interpreted the patient's data. RP drafted the paper. All authors read and approved the final manuscript.

\section{Funding}

The authors declare that they have no financial relationships with any organizations related to this case report.

\section{Availability of data and materials \\ All the data of this case are available.}

\section{Ethics approval and consent to participate}

The patient has signed an informed consent form for all the diagnostic and therapeutic plans.

\section{Declarations}

\section{Consent for publication}

The patient has signed an informed consent form for this publication. Written informed consent was obtained from the patient for publication of this case report and any accompanying images. A copy of the written consent is available for review by the Editor-in-Chief of this journal.

\section{Competing interests}

The authors declare that there is no conflict of interest.

\section{Author details}

${ }^{1}$ Department of Obstetrics and Gynecology, Firoozgar Hospital, Iran University of Medical Sciences, Tehran, Iran. ${ }^{2}$ Department of Pathology, Jam Hospital, Tehran, Iran. ${ }^{3}$ Department of Obstetrics and Gynecology, Jam Hospital, Fajr Street, Motahari Street, 1588657915 Tehran, Iran.

Received: 14 April 2021 Accepted: 28 October 2021

Published online: 28 November 2021

\section{References}

1. Shapiro E, Strother D. Pediatric genitourinary rhabdomyosarcoma. J Urol. 1992;148(6):1761-8

2. Miller RW, Young JL Jr, Novakovic B. Childhood cancer. Cancer. 1995;75(1 Suppl):395-405.

3. Cree IA, White VA, Indave BI, Lokuhetty D. Revising the WHO classification: female genital tract tumours. Histopathology. 2020;76(1):151-6.

4. Mallmann P. Uterine sarcoma-difficult to diagnose, hard to treat. Oncol Res Treat. 2018;41(11):674.

5. Pinto A, Kahn RM, Rosenberg AE, Slomovitz B, Quick CM, Whisman MK, et al. Uterine rhabdomyosarcoma in adults. Hum Pathol. 2018:74:122-8.

6. Mbatani N, Olawaiye AB, Prat J. Uterine sarcomas. Int J Gynecol Obstet. 2018;143(S2):51-8.

7. Okada DH, Rowland JB, Petrovic LM. Uterine pleomorphic rhabdomyosarcoma in a patient receiving tamoxifen therapy. Gynecol Oncol. 1999;75(3):509-13.

8. Parra-Herran C, Howitt BE. Uterine mesenchymal tumors: update on classification, staging, and molecular features. Surg Pathol Clin. 2019;12(2):363-96.

9. Williamson D, Missiaglia E, de Reyniès A, Pierron G, Thuille B, Palenzuela G, et al. Fusion gene-negative alveolar rhabdomyosarcoma is clinically and molecularly indistinguishable from embryonal rhabdomyosarcoma. J Clin Oncol. 2010;28(13):2151-8.

10. Ferguson SE, Gerald W, Barakat RR, Chi DS, Soslow RA. Clinicopathologic features of rhabdomyosarcoma of gynecologic origin in adults. Am J Surg Pathol. 2007:31(3):382-9.

11. Ricciardi E, Plett H, Sangiorgio V, Paderno M, Landoni F, Aletti G, et al. Adult primary cervical rhabdomyosarcomas: a multicentric cross-national case series. Int J Gynecol Cancer. 2020;30(1):21-8.

12. Raney RB, Maurer HM, Anderson JR, Andrassy RJ, Donaldson SS, Qualman SJ, et al. The Intergroup Rhabdomyosarcoma Study Group (IRSG): major lessons from the IRS-I through IRS-IV studies as background for the current IRS-V treatment protocols. Sarcoma. 2001;5(1):9-15.

13. Elsebaie MA, Elsayed Z. Is fertility-preservation safe for adult nonmetastatic gynecologic rhabdomyosarcoma patients? Systematic review and pooled survival analysis of 137 patients. Arch Gynecol Obstet. 2018:297(3):559-72.

14. Ferrari A, Dileo P, Casanova M, Bertulli R, Meazza C, Gandola L, et al. Rhabdomyosarcoma in adults. A retrospective analysis of 171 patients treated at a single institution. Cancer. 2003;98(3):571-80. 
15. Bergamaschi L, Bertulli R, Casanova M, Provenzano S, Chiaravalli S, Gasparini P, et al. Rhabdomyosarcoma in adults: analysis of treatment modalities in a prospective single-center series. Med Oncol (Northwood, London, England). 2019;36(7):59.

16. Fadare O, Bonvicino A, Martel M, Renshaw IL, Azodi M, Parkash V. Pleomorphic rhabdomyosarcoma of the uterine corpus: a clinicopathologic study of 4 cases and a review of the literature. Int J Gynecol Pathol. 2010;29(2):122-34.
17. Hart WR, Craig JR. Rhabdomyosarcomas of the uterus. Am J Clin Pathol. 1978;70(2):217-23.

\section{Publisher's Note}

Springer Nature remains neutral with regard to jurisdictional claims in published maps and institutional affiliations.
Ready to submit your research? Choose BMC and benefit from:

- fast, convenient online submission

- thorough peer review by experienced researchers in your field

- rapid publication on acceptance

- support for research data, including large and complex data types

- gold Open Access which fosters wider collaboration and increased citations

- maximum visibility for your research: over $100 \mathrm{M}$ website views per year

At BMC, research is always in progress.

Learn more biomedcentral.com/submissions 